\title{
Changing Veterinary Knowledge
}

By 1975, the existence of tuberculous badgers - and the idea that they could be responsible for the persistence of TB in British cattle herds-had solidified from a relatively obscure idea of some farmers and veterinarians into a still uncertain but rapidly cohering fact. This knowledge-and the risks it posed for human, domestic and wild animals-spurred the previously unrelated communities involved with badgers and with bTB to work together. In turn, this created new collaborative networks committed to understanding the new problem of badger/bTB. The Ministry for Agriculture, Fisheries and Food (MAFF) had moved from a local veterinary officer finding a single dead badger during the spring of 1971 to major investment in research and a national-scale culling policy. While policymakers' attempts at inclusive working, enlisting the help of farmers, landowners, naturalists and badger advocates had been strikingly successful, fractures were appearing. This middle section of the book will investigate what happened next, with the aim of understanding how and why participants in today's knowledge controversy over badgers and bTB have come to have such dramatically different perspectives. To that end, the next three chapters will investigate in depth the knowledge, expertise, working practices and practical goals of three key 'epistemic communities' that developed around badger/bTB over the following twenty years: animal health, disease ecology and badger protection. ${ }^{1}$ In turn, each will be placed into the broader historical and institutional contexts of their formation in midtwentieth-century Britain prior to the connection of badgers and bTB. 
This chapter will explore the worlds and work of the animal bealth epistemic community, comprising field and research veterinarians, policymakers and politicians in MAFF; veterinarians in clinical practice; farmers; and their representatives. It will pick up from the longer history of tuberculosis outlined in Chap. 1, to overview the development of frameworks for regulating $\mathrm{bTB}$ in the UK. It will place these frameworks into the broader contexts of veterinary disease control, caring and ethical practices, mid-twentieth-century animal health policy, and the internal organisation of the Ministry. We will then return to the story of badger/bTB with MAFF's 'Bovine TB in Badgers' research and policy programme, launched in 1975, and follow the veterinary investigations carried out under this remit. As MAFF's researchers started investigating the traces left by $M$. bovis in wild and domestic animal bodies, its policy of culling badgers by 'gassing' was becoming controversial. The incoming Conservative government of 1979 hoped to settle criticisms by inviting an 'authoritative expert'-Lord Solly Zuckerman-to review the situation. Instead, Zuckerman's report drew further media attention to the issue, creating wider public controversy than before. In the final part of this chapter, we will explore the less famous 'son of Zuckerman' Dunnet review, published in 1986 and conducted by a multidisciplinary team of scientists. ${ }^{2}$ Even though the criticisms made by the Dunnet group were downplayed by MAFF, their recommendations were implemented, contributing to policy change and the fading of bTB away from public scrutiny during the late 1980s.

\subsection{Animal Health and Cultures of Caring FOR LIVESTOCK}

The practices of epistemic communities - as they work together to build reliable knowledge aimed at achieving shared policy goals-can also be understood as a product and producer of shared 'cultures of care', as discussed in Chap. 1. ${ }^{3}$ Shared understandings of what constitutes 'good care' co-produce shared understandings of 'good work', in human health, laboratory science, farming and veterinary practice. ${ }^{4}$ I will use these frameworks to analyse the intersecting cultures of care that have mutually shaped the working practices of the British state as it has sought to understand and regulate animal health over the past two centuries. Just as Dutch healthcare workers in the twenty-first century must balance their embodied, everyday, flexible and adaptive but ultimately disempowering 'logics of 
care' for patients with formalised, market-based but empowering 'logics of choice', which engage with the economic constraints of healthcare, the epistemic communities of badger/bTB have had to perform similar balancing acts. ${ }^{5}$ These interactions profoundly shape who makes policy and practical decisions about care and what decisions get made under any given set of circumstances.

This chapter will explore the particular cultures of care ${ }^{6}$ developed by the epistemic community involved with British animal health policy, and how they in turn have shaped MAFF's policies for controlling bTB over the past century. Originating in the interactions of farming and veterinary practices of care for individual animals, herds, owners and wider economic interests, animal health care involves long-established procedures and policies for preventing the spread of infectious disease in animals. Often described as 'stamping out', these involve the slaughter of infected individuals and their immediate contacts, while also controlling the movement of other animals in affected areas. ${ }^{7}$ Variations on this practice are still deployed worldwide to manage infectious diseases in livestock, from bTB to foot and mouth disease (FMD) to influenza. For those accustomed to the elaborate, patient-focused, life-preserving techniques of modern human medicine, this way of working can be a shock. While veterinary care of companion animals in rich countries increasingly converges with human medical practice, using complex surgical and technological interventions, the underlying ethical basis of most animal health practice is quite different. Unlike human medicine, which tends to prioritise the preservation of life, farmers and veterinarians place a greater emphasis on preventing animal suffering. In practice this means that sick animals in pain or distress are more likely to be killed (euthanised, put down, put to sleep), rather than undergoing stressful, painful or expensive treatments. ${ }^{8}$ Veterinary care is also influenced by the wishes of the patient's owner (rather than patients themselves, who are legally property), particularly because animal healthcare tends to be a commercial enterprise, creating different dynamics around the 'logics of choice' and patient agency. ${ }^{9}$ This can make ethical decision-making for veterinarians morally and emotionally fraught, guided as it must be by owners' relationships with their animals (from deep emotional connections through to bald assessments of financial value). ${ }^{10}$ These decisions often bring to the fore clear tensions between the 'theory' of veterinary scientific evidence and the 'practice' of veterinary clinical and farming animal care, which must be negotiated on an ongoing basis. ${ }^{11}$ 
Such trade-offs have also been shaped by the type of animal involved and the societal roles that it has been assigned by the human society it lives in. While pets are cared and mourned for, other animals are not so fortunate. The balancing of life/death and care/suffering changes for livestock and working animals; is deeply contested for wild animals; and those designated as pests receive hostility rather than any form of care. ${ }^{12}$ The history of the profession also reflects our changing relationships with animals: while in Britain today the majority work with companion 'small animals' and there are such things as wildlife veterinarians, these are relatively recent trends. ${ }^{13}$ The origins of the veterinary profession instead lie in providing medical care for animals doing important work. It was the importance of horses (as military, transport and agricultural muscle) which led to the founding of the first veterinary schools in France and Britain in the late eighteenth century. ${ }^{14}$ Veterinarians did not become routinely involved in the treatment of farm animals until later, following a series of battles to establish their professional status (distinct from doctors and from those involved with animal husbandry). ${ }^{15}$

The arrival of rinderpest in the UK in 1865 devastated British horses and livestock, creating a major driver for the establishment of the veterinary profession, embedding and intertwining their work into the affairs of the state via concerns about agricultural productivity and (human) public health. ${ }^{16}$ The government formed a Veterinary Department to deal with the problem, setting the course towards developing structures for state interventions to control animal disease. Even though British veterinarians struggled with disciplinary rivalries with human public health experts, following a series of reforms, they established themselves as a legally recognised profession in $1881 .{ }^{17}$ In 1893 the position of Chief Veterinary Officer (CVO) was created and has been filled ever since-given that the Chief Scientific Adviser was a mid-twentieth-century invention, this probably makes the CVO the most long-standing expert advisory role in British government. ${ }^{18}$ Over the following decades, veterinarians extended their purview beyond rinderpest and establishing a network of veterinary inspectors qualified to identify diseased meat and animals. They developed dual roles: initially field-based, problem-solving 'practical men', and latterly laboratory and research-oriented 'scientific experts'. Following the end of the First World War, veterinary services were consolidated under the newly formed Ministry of Agriculture and Fisheries, bringing together the previously separated roles of policy enforcement and disease diagnosis. ${ }^{19}$ Key government institutes for animal health research were established at 
this time, including the Central Veterinary Laboratory (1917) and Pirbright Experimental Station (1924) ${ }^{20}$ While vets have maintained their professional role within government, they have experienced an ongoing process of internal reorganisation, repeatedly bringing together and separating their policy-implementing and scientific-researching functions. ${ }^{21}$

As well as the obvious risks of zoonosis (in diseases like bTB), infectious diseases affecting livestock alone (such as FMD) are managed partly for welfare reasons, but also because they bring with them economic risks. These manifest in the death of infected animals as well as suppressed productivity (of, for example, meat and milk). Therefore, policy decisions about infectious diseases in livestock were, and still are, motivated by a further logic - of cost, operating in the financial interests of animal owners and the wider economy. Therefore, veterinarians and policymakers concerned with animal health look beyond the individual patient to think about welfare and the spread of disease across herds, flocks and wider populations, further modifying practices of care. ${ }^{22}$ As 'stamping out' was elaborated, it required the detection of disease carriers as well as sick animals, driving the development of technologies for diagnosis and surveillance of microorganisms. This eventually led to what is described today as 'test and slaughter' regimes for animal disease control (which do as the name suggests: positive animals and their herd-mates are culled), an elaboration of the stamping-out approach. By the mid-twentieth century, stamping-out regimes were considered within animal health to be reliable, tried and tested. However, they were not always successful and continued to be controversial, particularly in relation to proposed alternative solutions such as vaccination. During FMD outbreaks in Britain in the 1950s, proponents of vaccination objected to what they saw as 'barbaric and medieval' and 'unscientific' disease control policies. ${ }^{23}$ While MAFF prevailed at the time, continuing with stamping out in their struggles with the much larger FMD outbreak of 1967-1968, the vaccination controversy returned during 2001, when around 6 million animals were slaughtered, creating a spectacle that made the consequences for animals dramatically visible to wider publics. ${ }^{24}$

The animal health epistemic community is not only comprised of veterinarians, policymakers and politicians, but also farmers: bound by these regulatory systems and (partly) in whose interests they had been developed in the first place. As I discussed at the beginning of this book, the voices of farmers themselves are often conspicuously absent from archival MAFF correspondence about bTB. When they do feature it is usually as 
correspondence with the National Farmers Union (NFU), which paradoxically is regarded by policy scholars as an exemplary 'policy insider'-a non-governmental body with close working connections with policymakers. ${ }^{25}$ Animal health cultures of care (balancing care, choice and cost) inside government in the UK have therefore formed in dialogue with the parallel cultures of care of farmers-albeit mediated through the NFU. We already know that 'good care' is co-produced by ideas and practices of 'good farming' - fundamentally farmers need their animals to thrive, but must also see livestock through to slaughter and ultimately make enough money to live. ${ }^{26}$ Agricultural workers constantly negotiate animal agency, expressed as a willingness or otherwise to cooperate with being herded, milked, confined, mated and medically treated. ${ }^{27}$ This constant negotiation-with the agency of their charges, as well the uncertainties of wider environments - has created cultures of care which help manage these uncertainties. Good farming is often bound up with ideas of stewardship: long-term care of a specific place, including the plants and animals living there. Farming care is-like traditional medical care-embedded, relational and fundamentally parental, in that the carer holds most of the power and agency in the relationship. It often involves understandings of human-environment relations which see people as holding responsibility for maintaining and controlling the 'balance of nature'. ${ }^{28}$ Social research into the difficult, distressing and dirty work of killing animals shows how farmers must try to manage these contradictions, negotiating paths between emotional connection and disconnection. ${ }^{29}$ While such negotiations are far from easy, it does seem that for most farmers at least, the death of their animals at slaughter for meat production is understood as a 'good death'-one which happens at the right time, without excessive cruelty and to serve an ultimate purpose-to provide people with food and income for the farm. ${ }^{30}$

The premature illness and/or death of livestock can therefore disrupt the delicate balance of human-animal relations on a farm. This is where farming, veterinary and animal health policy cultures of care come into conflict, particularly when the last is practised to protect populations. ${ }^{31}$ When livestock animals are slaughtered to prevent the spread of infectious disease, the deaths happen in an untimely and disorderly fashion, while control over the situation (a key aspect of farming care) is removed to the state. The following quote is from an anonymous account published in Farmers Weekly in 1973, but barring minor details it could easily be from the present day: 
Within 14 days, we had Ministry orders that the whole milking herd had to be slaughtered. One calf was slaughtered and found to have had nothing wrong, so the other 46 were given a second chance. A further test has been ordered for them and we are waiting for that. If they go down I don't know what I shall do. These are all I have left from a 10 year policy using nominated bulls on my best cows. As a result of what has happened, I have my fixed costs relentlessly going on, and until I restock I have no income apart from interest on the compensation payment. ${ }^{32}$

Despite financial compensation, the abrupt ending of their animals' lives, cessation of these relationships and disruption of day-to-day life was, and continues to be, a source of intense distress to many farmers. The loss of an entire herd entails a further disruption of farming 'stewardship' care, as herds also represent past and future care of lineages and land. ${ }^{33}$ State disruption to these routines of care engenders a sense of helplessness and resignation, making it harder to persuade farmers to take action to control the spread of infection in farm spaces. Paradoxically this can also be used to justify taking action against badgers, while others express distress and scepticism in the face of state culling policies. ${ }^{34}$ Stamping out has tended to be adopted by richer countries with the resources to implement it, easily controlled borders (enabling them to exclude reinfection from elsewhere in the world), and the political or economic clout to only trade with others adopting similar regimes. ${ }^{35}$ In the colonial era it was implemented to the benefit of settler farmers and undermined traditional, locally developed husbandry practices; these inequities persist in today's regimes of global and veterinary public health. ${ }^{36}$ This pattern is also present domestically, whereby the costs and benefits of such policies have tended to work in favour of landowners, larger farms and elite breeders, and against smaller-scale producers. ${ }^{37}$ While in recent years there has been a greater emphasis on government working in 'partnership' with farmers to reshape disease control policies, it is questionable to what extent this has made any difference to these feelings of helplessness in the face of infectious disease. ${ }^{38}$ Even though bTB is a manifest disease problem for humans and animals elsewhere in the world, in the UK it rarely poses direct health risks. As we will explore later in the book, while these risks can be minimised, the regulatory policies that make this possible have brought with them new economic, social and emotional risks, in turn fuelling public contestation of those policies. 


\subsection{MAFF's 'Bovine Tuberculosis in Badgers' Research Programme}

To pick up our story from the end of Chap. 2, by 1975 MAFF had announced a new approach to the transformed problem of bTB in badgers, comprising a state-led culling policy; an inclusive Consultative Panel advising policymakers; and major investment in new research. While public statements emphasised MAFF's decisive policy action, the scale of the proposed research effort tacitly acknowledged how little was understood about the situation. The 'Bovine Tuberculosis in Badgers' research programme involved work across several sites by multiple disciplinary specialists. It expanded and formalised the preliminary work on field epidemiology, pathology, bacteriology, immunology, transmission, the effectiveness of culling, and the behaviour and ecology of badgers. The latter work was mostly conducted by field biologists located in MAFF's Infestation Control Division and will be discussed in the next chapter. Here we will concentrate on the veterinary side of MAFF's research effort. To understand fully how these multiple policy and research actors were working together at the time, we need to take a brief detour into the wonderful world of UK government research and organisational structures within and beyond MAFF. Mirroring wider political turmoil, the early 1970s was a period of extensive change within civil service research. Financial tensions combined with wider debates about research-policy relations within government led to the commissioning and publication of the Rothschild Report in 1971, which proposed that 'applied' research be relocated from the (independent) research councils into relevant ministries. ${ }^{39}$ In parallel, these drivers had instituted major changes in government agricultural research, with MAFF forming a new umbrella organisation, the Agricultural Development and Advisory Service (ADAS) the same year. ADAS brought the State Veterinary Service (SVS) together with other agricultural experts, including the Infestation Control Division (ICD), crop research, and the pre-existing National Agricultural Advice Service, which provided expert advice to farmers. This move separated the SVS from the policy-facing Animal Health Division. ADAS combined advisory, research and policy implementation roles: this structure continued until another round of reorganisation (and privatisation) during the late 1980s. ${ }^{40}$ The organisation of the SVS itself remained broadly unchanged, comprising three subsections: field services, veterinary investigations (field epidemiology) and the Central Veterinary Laboratory 
(CVL). The SVS was overseen by the CVO and centralised management, but all three divisions maintained considerable autonomy: the CVL in its main location in Weybridge, and the field and investigation services through MAFF's network of regional offices. ${ }^{41}$

Roger Muirhead, the SVS Veterinary Officer who had found tuberculous badgers, worked out of MAFF's divisional office in Gloucester. After 1975 regional investigations were further supported and supplemented by the SVS, with new veterinary investigation (VI) centres opening in Gloucester and Truro and new work initiated at the CVL. John Gallagher was relocated to Gloucester and started worked closely with Muirhead and other colleagues to formalise the existing data and publish their findings. Once they started looking for tuberculous badgers, they found more and more of them, spread across an increasingly wide area. Many of these animals had extensive lesions, some in the lungs but mostly in the lymph nodes and kidneys, containing huge numbers of bacilli. ${ }^{42}$ The VI team at Gloucester also researched the viability of $M$. bovis bacilli in badger bodily fluids, carcasses, 'infected setts' and soil samples. After several months, they were unable to detect the bacteria, leading them to the conclusion that infected materials were likely to 'self-sterilise' in the field. ${ }^{43}$ Instead they argued that the major transmission route from badgers to cattle was likely to be via pasture contaminated with infected urine and spit. ${ }^{44}$ Further pathology investigations concluded that bTB was the major cause of sickness and death in badgers in Gloucestershire at the time, and highlighted the role of bite wounds for badger-badger transmission. The paper also drew attention to externally visible symptoms of bTB in badgers, such as emaciation and overgrown claws. ${ }^{45}$

At the CVL, a small 'colony' of wild badgers were brought in to study them under laboratory conditions. They were inoculated with $M$. bovis from infected cattle and groups of calves were inoculated vice versa, demonstrating that cross-infection was possible. ${ }^{46}$ When the infected badgers were housed with calves, the cows became sick, surviving between six months and a year after exposure. ${ }^{47}$ By 1976, MAFF had already concluded that 'badgers are susceptible to the disease and can play a significant role in transmitting infection to cattle'. ${ }^{48}$ Badger immune responses to $M$. bovis were investigated, and CVL scientists quickly found that standard tuberculin testing did not work. ${ }^{49}$ Towards the end of the decade, VI officers (field epidemiologists) and CVL researchers started working on techniques to identify different strains of $M$. bovis in cattle and badgers in different areas, suggested by variations in disease virulence..$^{50}$ Both groups 
contributed to ongoing efforts to identify and map bTB incidence, continuing to follow the traces of badgers and M. bovis in the environment. Samples of bodily fluids were tested for the bacterium, alongside the bodies of badgers killed during culling and research, plus those of animals that had been found dead either from disease or road traffic accidents (RTAs). From early in Muirhead's investigations in Gloucestershire, farmers and other members of the public had been bringing dead badgers to MAFF officers. In 1976, MAFF decided to capitalise on this enthusiasm, instituting a formal 'Badger Survey', requesting that any carcasses found by members of the public be brought to the nearest Ministry office, and recording the resulting data. This project-which would now be described as 'citizen science'-continued until $1990 . .^{11}$

Finally, veterinary researchers and field staff worked in collaboration with ICD on a series of 'clearance trials'-interventions designed to test the effect of clearing all badgers from a given area. ${ }^{52}$ The first of these took place at Steeple Leaze Farm in Dorset, which had experienced unusually high rates of cattle disease. Under pressure from the farmer and local NFU, MAFF prioritised the case, with the trial starting as soon as gassing was legalised..$^{53}$ The second intervention took place around Thornbury, near Bristol and was described as 'an experimental badger clearance programme'. ${ }^{54}$ The idea was to remove all badgers from an area clearly bounded by rivers and motorways, in order to prevent the animals 'recolonising', and observe the effects on bTB in cattle. ${ }^{55}$ In both interventions all badger setts had to be gassed repeatedly as field officers discovered new animals moving into the area: the clearances lasted for about five years. Despite these difficulties, MAFF persisted with removing badgers from both intervention areas and by 1979 reported that badgers had been successfully cleared: crucially they also reported that there had not been any new outbreaks of bTB in cattle herds. ${ }^{56}$ The new research programme reported to MAFF every year or so, summarising key findings and new lines of enquiry: a condensed version was included in the CVO's Annual Report. Aside from some early publications in the Veterinary Record, much of this work was not published in peer-reviewed journals until well into the 1980s, and not until 1995 in the case of the Thornbury clearance trial. ${ }^{57}$ While these projects were long term by design, given MAFF's awareness of the sensitivity of the topic, perhaps there were qualms about making the finer details of this research public. It seems that during the 1970s the SVS considered this internal reporting and the advice of their 
own experts to be an adequate standard of evidence on which to build policy.

The Bovine Tuberculosis in Badgers reports were used to communicate the situation upward to senior civil servants and ministers in MAFF and outwards to the experts and external policy interests represented in the Consultative Panel. Initially MAFF stressed the Panel's role in reviewing and approving policy, and the group convened three times a year. ${ }^{58}$ By 1975 MAFF had forged a consensus that the best route forward was to cull badgers using 'gassing': pumping a product called Cymag (sodium cyanide in powder form) into setts, where it reacts with moisture in the air to release hydrogen cyanide gas. The technique was already in use (by MAFF and private citizens) for 'pest control' of rabbits and moles and would have been widely familiar (Fig. 3.1 depicts a MAFF gassing crew and their gear in situ in Gloucestershire). ${ }^{59}$ Once the law had been changed to make this possible, the policy was rapidly rolled

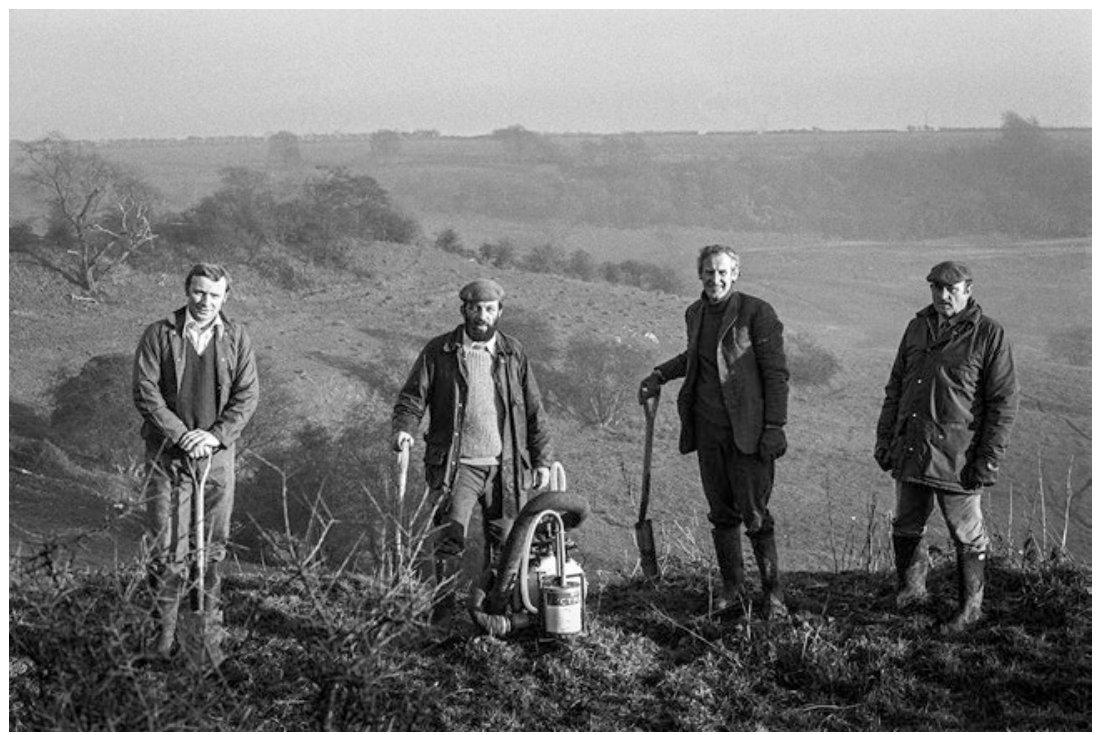

Fig. 3.1 'The badger brigade and their gassing machine near Dursley'-photograph by Jane Bown https://en.wikipedia.org/wiki/Jane_Bown. Source: 'New battle over the "bad" badgers-George Brock', Observer, 12 Dec. 1976, 3. Reproduced by permission of Guardian News and Media Ltd 
out from 1976 onwards. The formal procedure, known as a 'fire brigade' operation, involved gassing all setts in the area of a bTB outbreak where 'no other source of infection has been revealed' and where local badger traces tested positive for $M$. bovis. ${ }^{60}$ Thirty-three culling operations were conducted in 1976, rising to approximately fifty per year through 1977$1978 .{ }^{61}$ By the end of the decade MAFF was upbeat about their progress and confident that their research had confirmed that badgers should be targeted. ${ }^{62}$ They consolidated the culling policy, introducing further legislation granting officers powers of entry to private land in four Control Areas spread across the South West of England. This led to a drop-off of the locally focused 'fire brigade' operations and a shift to wider-scale culling towards the end of the decade. ${ }^{63}$

Outside of MAFF, others were not so confident. Privately, the scientists and officers of the Nature Conservation Committee (NCC) - a Department for the Environment body responsible for conservation research and policy - continued to be highly critical of MAFF's scientific standards. ${ }^{64}$ Critically, the specialist consensus on gassing was not shared by wider publics or the media, and several local newspapers started campaigning against the policy. ${ }^{65}$ Meanwhile, the UK was weathering the ongoing instabilities of the 1970s. Following the 1975 referendum on membership of the European Economic Community (EEC), MAFF had been heavily occupied with negotiating and implementing the Common Agricultural Policy system of agricultural subsidies and trade agreements. Following the collapse of the Conservative Heath government in 1974, Labour took power but continued to weather political instabilities, with the resignation of Harold Wilson in 1976, and a further three years of minority Labour government under the leadership of James Callaghan. Following a period of prolonged recession and industrial unrest known as the 'Winter of Discontent', a Parliamentary vote of no confidence in Callaghan's government was passed on 28 March 1979, triggering a General Election on 3 May. While bTB was still a relatively obscure issue in and of itself, badger advocates had skilfully reframed the disease in terms of gathering wider concerns over agricultural intensification, environmental damage and livestock welfare. ${ }^{66}$ The incoming Conservative government, led by Margaret Thatcher, was elected on the strength of a modernising, reforming agenda. Badger/bTB had by that time been a thorn in the side of ministers and policymakers for nearly a decade. Was it time to think again? 


\section{3 'An Objective Look'}

The incoming Conservative government awarded the position of Minister of Agriculture to Peter Walker (a core member of the Heath administration) who had overseen the creation of an entirely new dedicated Department of the Environment in 1970s. Following the election in the spring of 1979 and a summer of anti-gassing protests, including a particularly difficult confrontation on Dartmoor, ${ }^{67}$ Walker announced that he had asked a fellow pioneer in environmental policy_Lord Solly Zuckermanto review the situation:

I have been concerned about the recent criticism of this Ministry's policy for dealing with badgers infected with bovine tuberculosis. The criticism has centred on the extent to which infected badgers are likely to pass on the disease to cattle and on the methods used to eradicate the disease. I have therefore asked Lord Zuckerman, President of the Zoological Society of London, to take an objective look at the problem and to give me his advice on the way it should be tackled in the future. I propose to make his findings public. ${ }^{68}$

Walker's press release invited anyone who wished to provide 'scientific evidence' to contact MAFF, and announced a moratorium on gassing 'beyond what is necessary to maintain freedom from the disease in areas that have already been cleared of it' ${ }^{69}$ Zuckerman was eminently well qualified: as well as his specialisms (zoology and physiology) and presidency of the Zoological Society of London, he had been involved with government enquiries on environmental pollution, FMD and rabies. ${ }^{70}$ His position as the first Chief Scientific Adviser to the UK government (retired), member of the House of Lords and an integral part of 'the Establishment' made him the quintessential authoritative expert of the time. From Walker's perspective, Zuckerman could be trusted to provide a clear analysis of the situation (which had become more complex as research on the topic had progressed), advise ministers on the best course of action and help to calm burgeoning controversy over badger culling.

Zuckerman's archives show that five years earlier, HRH Prince Philip, Duke of Edinburgh (also President of the World Wildlife Fund), had enquired about badgers and bTB as part of his regular correspondence with Zuckerman. 
My Dear Solly,

I hear that badgers are being blamed for the spread of various diseases among cattle and other domestic farm animals-particularly tuberculosis. Is this really possible? I'm afraid I don't really know by what means TB gets around.

Yours ever, Phillip. ${ }^{71}$

Zuckerman made enquiries with MAFF, who passed on the information available internally at the time. He wrote back to Prince Phillip, forwarding the material with the statement 'It does look as though some guilt must attach to them [badgers]. ${ }^{72}$ This exchange highlights Zuckerman's unusual position working across the worlds of science, policy, agriculture, conservation and elite society. ${ }^{73}$ It also provides further evidence for the choice of Zuckerman to conduct the review, as a core and authoritative science-policy actor, who had recently stepped down from his formal role in government.

Zuckerman started to get correspondence almost immediately after the announcement, but he started work in earnest in the New Year, meeting with the CVO, senior MAFF officials and the Consultative Panel in London. He then visited the South West, where he consulted MAFF officers and policy teams in the area, alongside local farmers, naturalists and badger protection campaigners. While compiling the report, he consulted at least twenty individuals, collated submissions from nineteen external organisations, reviewed the scientific literature and received ninety-eight written submissions from individuals, including farmers, MPs, scientists external to MAFF, naturalists, animal welfare campaigners and members of the public. ${ }^{74}$ The report was delivered to the Minister in August 1980 and was characteristically precise, comprising a review of the key scientific issues, followed by a section rebuffing various critiques of MAFF's policy and ending in a series of recommendations. Zuckerman maintained his earlier position: that MAFF's research had confirmed a connection between $\mathrm{bTB}$ in badgers and cattle, and that the current policy was the correct course of action and should continue. He drew upon medical analogies to support the various lines of veterinary enquiry which had been conducted; and cited the existing consensus that gassing was the most effective and humane technique available. Ever the scientist, Zuckerman acknowledged that there was still much to learn, recommending an expansion of MAFF's existing research. He also outlined key areas for further investigation, including specific research 'to devise 
improvements in the gassing procedures that have been used hitherto' ${ }^{75}$ MAFF regarded the report as a vindication and a return to business as usual, announcing the resumption of gassing with immediate effect. ${ }^{76}$ To further support their case, MAFF released figures suggesting there had been a recent increase in bTB rates in cattle in the South West, alongside findings of a 'significant' number of infected badgers, which they attributed to the suspension of gassing. ${ }^{77}$

The publication of the report (in October 1980) prompted more press and other media than ever before (see Fig. 7.1). However, the media and public responses were very different to MAFF's. Zuckerman's role was usually reported quite neutrally, describing him as a scientist whose 'findings' supported the government's position. Others were more sceptical of his neutrality, using headlines such as 'RUN, BADGER, RUN: The scientists are after you! ${ }^{78}$ Following the initial report the story persisted as a series of organisations and public figures took the opportunity to get a wider airing for their criticisms of MAFF. While key groups such as the RSPCA and NCC (who had both privately raised concerns about gassing) publicly supported Zuckerman, other scientists and badger protection campaigners were highly critical. ${ }^{79}$ The Mammal Society wrote to Nature to dispute Zuckerman/MAFF's claim that gassing had reduced bTB in cattle, ${ }^{80}$ while ecologist Hans Kruuk commented that 'the evidence presented does not warrant the conclusions' ${ }^{81}$ Zuckerman was incensed and immediately defended himself, responding with commentaries in the Sunday Times and in Nature, in which he restated his main arguments and disputed the 'spurious criticisms' that had been made. ${ }^{82}$ The argument continued on the pages of both Nature and New Scientist via letters and articles throughout 1981 and into 1982, drawing in a wide range of correspondents, including the CVO and Martin Kaplan-an eminent TB expert in the WHO. ${ }^{83}$ The controversy was not limited to the scientific press and also took place in mainstream media coverage. This included further expert criticisms, badger persecution, more protests, a lengthy piece in the glossy Observer Magazine from BBC presenter Phil Drabble (including pictures of snared badgers and gassing operations) and scathing commentary from columnist Auberon Waugh. ${ }^{84}$

Zuckerman was incensed by these responses, firing off a series of letters to senior MAFF officials, the Minister, John Maddox (the editor of Nature) and scientific colleagues, including the head of the Natural Environment Research Council (Hans Kruuk's boss). In these letters he 
demanded retractions and suggested that Drabble (among others) be sued for libel. Zuckerman's correspondents advised him against this:

... there is little doubt that it is defamatory, and defamatory of you. ... But, having said this, I would very much discourage you against bringing a libel action in these circumstances. It is obviously an issue on which people feel very strongly and are therefore moved to extravagant and reckless utterance. With the picture of assassinated badgers in front of their eyes there is no knowing what a jury would do and it would only require three members of the jury to provoke a disagreement. Also it is the easiest thing in the world to work up hostility to members of the Establishment and certainly to Established scientists. Moreover, the motivation of the author is, on the face of it, not hostility to you but affection for badgers. ${ }^{85}$

This is quoted at length not only for a sense of the likely weight of public opinion at the time in a legal context, but also for the reference to 'the Establishment', at a time when traditional British power structures (including science) had been under widespread criticism for years. Zuckermanas a senior scientist, government policy adviser and friend of the Royal Family — would have been seen by both friends and enemies as such-note also his formal suit in the Private Eye cartoon (Fig. 3.2).

By the end of 1981 the media coverage had faded away. However, another storm was quietly brewing for Zuckerman and MAFF. As requested, MAFF had commissioned scientists at the Chemical Defence Establishment (CDE), Porton Down, to conduct further research on the effects of cyanide on badgers. For several years, wildlife groups had been reporting stories of distressed animals emerging from gassed setts: at the urging of RSPCA's Wild Animals Committee, ICD, CDE and the RSPCA started discussing further research early in $1979 .{ }^{86}$ MAFF had continued with gassing, based on long experience of its speedy and lethal effect on other mammals and, following the snaring imbroglio (see Sect. 2.3), lack of other options. Following the publication of Zuckerman's report, a contract was placed with CDE to carry out this work, which was completed by March 1982 . The scientists at Porton applied standard laboratory dose-response techniques to determine the correct concentrations of hydrogen cyanide required to kill badgers. They used ferrets as a 'model organism': a sensible choice, given the two species' shared membership of the Mustelid family, the well-established tradition of working with ferrets in biomedicine, and the likely political implications of conducting laboratory experiments 


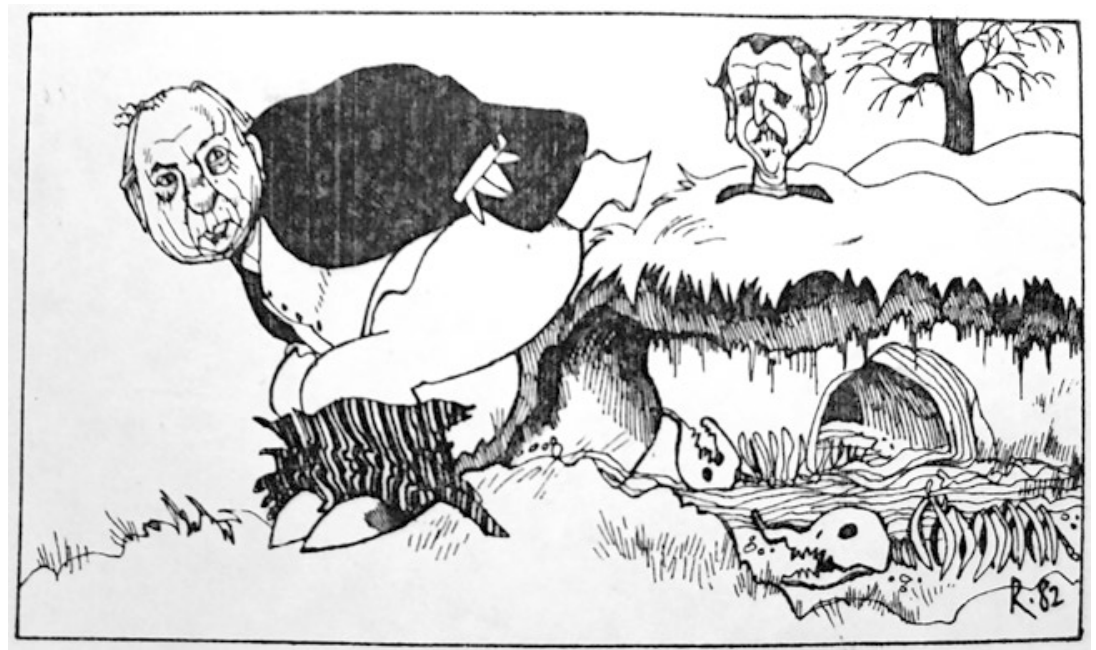

Fig. 3.2 Cartoon from Private Eye, January 1982. Zuckerman is depicted on the left, having 'gassed' a badger sett, while the Minister (Peter Walker) appears on the right, popping up for air (artist credit: Willie Rushton). Reproduced by kind permission of Private Eye magazine/The Estate of Willie Rushton ${ }^{98}$

on large numbers of badgers. ${ }^{87}$ Three groups of about sixty ferrets were exposed to a cyanide spray in a sealed chamber, respectively for one, five and twenty-five minutes. The Porton scientists also exposed four wild badgers to cyanide, to directly observe the effects on Meles meles. The findings were dramatic: unbeknownst to anyone, it turned out that mustelids were unusually resistant to cyanide poisoning. The ferrets required extremely high doses to kill them and cyanide 'was not as effective at producing rapid unconsciousness as had previously been thought'. ${ }^{88}$ The badger experiments were particularly alarming: only one animal died, slowly, and several showed obvious signs of distress before collapsing. Unlike other mammals, which tend to recover from a sublethal dose of cyanide with no ill effect, the ferrets and badgers that survived showed longer-term symptoms, including vomiting and paralysis. ${ }^{89}$ Badgers were living up to their popular reputation as extraordinarily tough animals who are very difficult to kill.

Upon receipt of the CDE Porton research, MAFF convened an emergency meeting of senior officials. They agreed to continue with gassing but to warn the Minister 'of potential difficulties' while they sought a 
meeting with the CDE scientists to 'to ascertain their interpretation of the results and to explore, if necessary, alternative methods of control': a confidential summary of the situation was circulated to senior MAFF staff. ${ }^{90}$ The meeting with CDE took place on 15 June, at which the generalisability of the experiments and the implications for policy were discussed. Some SVS staff were sceptical, suggesting that the effects of Cymag itself (sodium cyanide powder, not the hydrogen cyanide gas used in the CDE experiment) should be properly tested under field conditions. However, the CDE scientists defended their work, arguing that this would be impractical, expensive, unethical and likely to demonstrate even less effectiveness. They emphasised that they 'did not believe that hydrogen cyanide gassing was a humane way of killing badgers', conflating the two. ${ }^{91}$ The implications of earlier work done by MAFF investigating Cymag distribution in real setts was also explored-it had been found that the poison ended up unevenly spread through the complex of tunnels. CDE believed it likely that in the field badgers were dying slowly from the lower doses, and that the problems of getting poisons into the furthest reaches of a sett meant that any other substance (e.g. carbon monoxide) would have similar problems. ${ }^{92}$

Following these deliberations, the civil servants rapidly reached agreement on what to do next and the Minister was briefed: 'There must be serious doubt as to whether hydrogen cyanide gassing of badgers is the most humane method of despatch. Nor can we be sure that badgers do not escape from gassed setts. ${ }^{93}$ In other words, MAFF policy team were concerned not only that gassing was cruel (and would be unacceptable for wider publics), but that it was not fully effective for disease control purposes. They recommended that gassing be suspended immediately. With snaring and gassing now ruled out, officials now turned towards an effective yet time-consuming procedure: combining cage-trapping and killing the animals with a direct shot. Peter Walker wrote to Lord Zuckerman on 28 June regarding the 'very disturbing' findings, requesting an urgent telephone call. ${ }^{94} \mathrm{He}$ then formally made the decision to stop gassing, and met with the Consultative Panel on I July to inform them of the situation, while MAFF announced the Minister's statement at the same time. This process had de facto excluded the Panel from decision-making. In their briefing notes to the Minister, animal health officers had considered the possibility of consulting the Panel and dismissed it on the grounds of urgency, assuming that they would agree with the decision to stop gassing immediately. ${ }^{95}$ Over the course of the Zuckerman review process, 
the role of the Consultative Panel had shifted from needed policymaking partners to a legitimising rubber-stamp.

The immediate effect was to reopen the public controversy by prompting further media coverage and criticisms of government. ${ }^{96}$ This policy reversal had the effect of undermining the authoritative report that MAFF and Zuckerman had thought would calm things down, even though it was a direct consequence of following scientific recommendations. Zuckerman's interventions in defence of MAFF had probably exacerbated this problem, by reinforcing the impression that his position was borne of a desire to defend government and the status quo. The Mirror's editorial page was particularly damning: 'It has taken seven years of protests to stop this vile slaughter of one of God's loveliest creatures. All that time the cyanide killers were lying through their teeth when they said it didn't hurt. The arrogant know-alls at the Ministry of Agriculture and the RSPCA who wouldn't listen deserve to be put in badger sets themselves. And see how they like it. ${ }^{97}$ Instead of being treated as the senior scientist and respected government figure he had been through most of his career, Zuckerman found himself to be the target of invective and a figure of fun-as seen in the scatological response to the affair from Private Eye (Fig. 3.2).

From Zuckerman's correspondence, it seems that the hostile responses to the report took him entirely by surprise, and his zeal in rebutting critiques rapidly turned to dismay as he became more deeply entangled in the controversy. He wrote to a friend early in 1981, 'I have asked myself whether having now experienced this backlash I would have said yes so easily to Peter Walker's request when he put it over the telephone. I said yes, because I like Peter and because the way he explained the whole thing to me all that would be required would be a week's work: looking at documents and talking to people in his Department. ${ }^{99}$ Alongside formal submissions to the enquiry, Zuckerman received a large volume of private correspondence-which increased after the report was published. This included detailed scientific discussions, speculations, impassioned pleas both for and against culling, photographs of injured animals, jokes and a small but significant amount of personal abuse. Some of this material has been retained in the Zuckerman archive (in a folder marked 'Nut Letters'). It includes anti-Semitic abuse, accusations of Nazism, religious tracts and threats: for example, to put him on 'the other side of the bars' at London Zoo. ${ }^{100}$ Robert Armstrong, Secretary of the Cabinet Office, wrote to Zuckerman, 
Dear Solly,

I worry for you.

When I was driving to Dorset yesterday, I found myself behind an exceedingly dirty truck; and in the dirt on the back of the truck someone had scrawled in bold capital letters the legend

GAS LORD ZUCKERMAN.

Mrs. Murray strikes again, I suppose. ${ }^{101}$ But I really think that you should keep clear of the South West for the time being. I worry for you.

A Happy New Year to you both.

Yours ever, Robert. ${ }^{102}$

Around this time, Peter Walker wrote to Zuckerman apologising that, 'you are still in the thick of it'. ${ }^{103}$ While Zuckerman initially replied with a relatively upbeat note, remarking, 'I sincerely hope that I shall be able to get shot of the badgers and the enthusiasts before too long', the controversy was taking its toll. ${ }^{104}$ By this time he was well into his seventies and suffering increasing health problems, affecting his dealings with others: 'he began to be irritable and at times unreasonable, autocratic and impatient ... He became less and less prepared to take into account other views than his own.' 105 A month later Zuckerman wrote to Walker again: 'I have really had enough. I have now given up the better part of a year to the matter, and this I can ill spare at my time of life when I have other things I wish to do', ending the letter, 'Please, please, take over ...' Zuckerman urged Walker to encourage MAFF's 'veterinary and other scientists' to 'speak out' in the press. ${ }^{106}$ Walker replied expressing sympathy: 'It is monstrous that you should continue to be pestered. Do, of course, pass all correspondence and complaints direct to us and we will deal with this. ${ }^{107}$ However, MAFF continued with their existing strategy of formal press releases, ministerial statements and technical reports, while scientists working within the Ministry confined their public communication to occasional letters to editors. Zuckerman continued to pursue badger/bTB throughout 1981, but following the suspension of gassing in 1982, he appears to have abandoned the argument.

So why did Zuckerman take the position that he did? Many of his opponents assumed or implied that he was politically motivated and certainly Zuckerman was at the heart of the political and scientific Establishment. However, Zuckerman's annotations of the submissions and correspondence with actors in badger/bTB do not support this idea, although they do offer considerable insight into his thinking. While he was 
widely known as the head of London Zoo and was deeply involved in the formation of British environmental science and policy, ${ }^{108}$ he was an oldfashioned scientific polymath, with a primary training in medicinealthough he never practised, moving immediately into research in anatomy, primatology and physiology. ${ }^{109}$ However, as his secretary put it, Zuckerman 'did not suffer fools gladly'. ${ }^{110} \mathrm{His}$ post-report comment to Walker is key: 'I do hope that you agree that a channel has been given to me to stop the illiterate and unscientific campaign against MAFF's policies with regard to the badger.' ${ }^{\text {111 }}$ While he had considered all submissions and met with the full range of actors in badger/bTB, he regarded MAFF's veterinarians and scientists to have the most in-depth and legitimate expertise on the matter, reacting strongly against suggestions that the gassing policy was unacceptable to 'reputable scientists'. ${ }^{112}$ As we will explore in the next two chapters, the main criticisms of the Zuckerman report came from scientists-mammologists and ecologists outside of government-and from naturalists and animal advocates who had remobilised existing campaigns for badger protection around bTB. As we know from other scholarship on Zuckerman's life and work, while one of his specialisms was in primatology, he had little respect for field biologists, ethologists and ecologists, regarding their work to be less rigorous than his own laboratory-based approach. ${ }^{113}$

As well as responding in the media and threatening to sue, Zuckerman wrote privately to ecologist Hans Kruuk's superiors at the Institute for Terrestrial Ecology (ITE) (a government research institute under the aegis of the NCC) questioning 'the propriety of him, as someone who is supported by public funds, criticising a ministerial decision based upon the advice of people who know far more about tuberculosis in cattle than he does'. ${ }^{114}$ When this got nowhere Zuckerman then escalated to the director of the Natural Environment Research Council, complaining to them of 'the Institute of Celestial Ecology (Terrestrial Ecology is a fancy name for what an earlier generation of zoologists called "natural history")'. ${ }^{115} \mathrm{He}$ also wrote, 'As a zoologist and medical man I know of no one on its [the Mammal Society's] Council who, on the basis of experience, would be consulted on matters relating to the epidemiology of animal disease.'116 Privately, he was also highly dismissive of the expertise represented by MAFF's Consultative Panel, which 'was obviously set up as a PR body, consisting as it does of farmers, badger enthusiasts, etc. '117 This was also evident in his correspondence and comments about campaigners, who he also referred as 'enthusiasts'. Of naturalist Eunice Overend, he wrote, 'I have no doubts about Miss Overend's 
sincerity, but her "facts" happen to be wrong." 118 Zuckerman was even ruder about Ruth Murray, using two full pages of his report to attack 'Mrs Murray's' position (Murray contested that badgers did not suffer from bTB), which he argued amounted to 'unsubstantiated assertions'.119

These comments reflect Zuckerman's own hierarchy of expertise, with 'medical men' like himself and MAFF's veterinarians at the top, field biologists way down the list and untrained 'enthusiasts' at the bottom. ${ }^{120}$ As suggested by his self-description as a 'medical man', Zuckerman seemed to regard MAFF's veterinarians as equivalent to doctors and biomedical researchers, and as a senior policy adviser he would have been familiar with the 'stamping out' approach to disease control. An alignment with animal health cultures of care is also suggested by the prominence given to farmer testimony in the report, awarded an eight-page appendix. ${ }^{121}$

From his point of view, Zuckerman had done precisely what Walker had asked, in the same way he had always conducted such reviews in the past. While he had worked as the government's Chief Scientific Adviser from 1964 to 1971, upon his retirement he stood back from the day-to-day workings of government science and moved to Norfolk. This meant that by 1979 he would have been less directly exposed to the broader political changes of the time relating to science, the environment and policy. Even though (or perhaps because) Zuckerman had worked through the thick of the 1960s and 1970s 'sea change' in science-society, his reaction to 'enthusiast' criticisms of MAFF's research and policy was hostile and dismissive. ${ }^{122}$ When his report was publicly and virulently contested, he was surprised, defensive, upset and eventually exhausted. Rather than resolving the matter, the report instead prompted further media attention and public disagreement between experts. Zuckerman was further drawn into the controversy, due to his position as a public scientist and his own combative nature, which combined explosively with the indirect nature of MAFF's public communications. This pattern-of developing controversy, leading to an expert review (anticipated to resolve the problem), which then creates further controversy-was to set a course for badger/ bTB which persists into the present day.

\subsection{Research Expansion, Policy Tinkering}

Despite its association with the modernising Conservative Thatcher government, the Zuckerman report did not directly drive any change in bTB policy. Not only was Zuckerman a staunch supporter of the traditional 
animal health approach to disease control, the Minister Peter Walker (a moderate Conservative and member of the Heath administration) would also have been in favour of continuity. Instead it was Zuckerman's recommendation for further research, the CDE Porton scientists' entirely unexpected findings - and the unanimous conclusion that this made the gassing policy inhumane-which precipitated rapid policy change in 1982. Snaring had already been ruled out: with this finding taking gassing off the table, policymakers turned to the previously discarded option of cage-trapping. While the idea had been discarded due to the vulnerability of traps to 'interference', the tendency of the animals to get 'trap shy' and logistical complexities, trapping techniques had been refined in research contexts where catching live animals was necessary. Given the lack of alternatives, MAFF officials and the Consultative Panel rapidly agreed that trapping should be adopted to replace gassing as its main culling technique, developing standard procedures for field staff. ${ }^{123}$ Beyond this technological change, MAFF's overall policy course continued, albeit modified into a 'clean ring' strategy_of removing badger social groups in an increasing circle around an outbreak until a layer of uninfected animals was found and removed. ${ }^{124}$

Zuckerman's other recommendations included that another review be published in three years' time; that MAFF's existing research programmes should continue; and that mechanisms be created for the 'freer exchange of information' between Ministry staff, private veterinarians, naturalists and academic scientists. ${ }^{125}$ In 1982 MAFF set up a new Co-ordinating Group to pull together the various strands of bTB activity taking place across the department, as well as to 'act as a liaison point for outside research institutions and organisations involved in this work'. ${ }^{126}$ The ongoing research investigations were now being published in academic journals, all of which seemed to confirm the association between bTB in badgers and cattle. ${ }^{127}$ Collaborations between CVL and academic microbiologists had developed a method for identifying multiple strains of $M$. bovis, and tracing these suggested that the disease had jumped between the two species on more than one occasion. ${ }^{128}$ By this time the 'clearance trials' were showing even more striking results. MAFF officers had had to go to considerable effort to clear badgers from these spaces, re-culling periodically until 1982. In the Thornbury study area, the area had been recolonised by 1989 , but no infected badgers were found and there still were no herd 'breakdowns' (positive TB tests)-later SVS reported this effect persisting well into the 1990 s. ${ }^{129}$ Following the discovery of badgers' 
apparent lack of immune response to M. bovis, researchers at CVL focused on the key problem of diagnosis, developing new techniques for culturing the microbe in the lab, identifying multiple strains and attempting to apply BCG vaccinations to badgers. ${ }^{130}$ While these diagnostic problems knocked on to veterinary scientists' abilities to understand the epidemiology of $M$. bovis, nonetheless knowledge about badger/bTB had become much more sophisticated since the early investigations in Gloucestershire a decade previously.

MAFF's overall capacity to monitor, follow and understand the spread of infectious disease in animals had improved greatly, with increasing numbers of VI field officers and the establishment of a specialist Epidemiology Unit. This enabled SVS to start collating its disease control data nationally, providing statistical expertise to support policy surveillance and epidemiological research alike. ${ }^{131}$ As computers became cheaper and more widely used in government, the Unit adopted these technologies, creating a database to help them understand this increasing volume of data, including bTB surveillance data, the introduction of EEC standardised cattle testing and the new brucellosis eradication scheme. ${ }^{132}$ As data from the various field studies came in, the epidemiologists were able to start building up a picture of the movements of M. bovis in wildlife and how it might relate to that in cattle populations. This data, analysed inhouse and by externally funded researchers, had consistently found M. bovis in the badger population, but only sporadically in other wildlife or domestic species. ${ }^{133}$ Veterinary epidemiologist John Wilesmith had been recruited by Veterinary Laboratories Agency (VLA) in 1976 and was central to the new epidemiological work on bTB, including statistical analyses associating badger sett density with outbreaks of 'unknown origin' in cattle herds. ${ }^{134}$

The application of computing to epidemiology continued and expanded following the Zuckerman report, the advent of mathematical modelling techniques and MAFF's creation of a fully staffed Computer Unit in the SVS. ${ }^{135}$ With the advent of microcomputing, a Commodore 8096 PC was sent from CVL to Truro VI centre during 1982 so that staff could computerise badger data for later analysis. ${ }^{136}$ Veterinary Officer Roger Sainsbury, stationed at MAFF's Divisional Office in Truro, was greatly pleased by its arrival. Sainsbury was an electronics and home computing enthusiast, who had initially trained himself via PC magazines and then with Open University courses. ${ }^{137} \mathrm{He}$ realised that the badger data could be helpful for MAFF field investigations and built a similar database for 
infected cattle. However, this data was not in a format that was useful for field staff:

The vets were going out on field investigations with computer printouts of all the badgers and cattle infection that had been found locally. Sadly this was a complete waste of time, nobody looked at it. You couldn't visualise where the infected animals were on the ground. So it wasn't really very good ... So I thought a picture is worth 1000 words-why don't we try and display it graphically? I therefore wrote a TB mapping program which was much more useful. It was a very early example of a Geographical Information System (GIS). The locations of the cattle herds and badgers shown on the map acted as a key to find further information about these in the accompanying database. ${ }^{138}$

The program (TB Maps and Stats) projected MAFF's surveillance data for cattle and badgers onto the grid references of a map, creating a more sophisticated version of the hand-drawn mapping techniques used in Muirhead's early investigations (Fig. 2.1). The software was a great success and was rapidly integrated into the routine work of the SVS in areas where TB was a problem. ${ }^{139}$ TB Maps and Stats remained in use by MAFF and its successor, the UK Department of the Environment and Rural Affairs (Defra) until 2006, when Animal Health's national VetNet database was phased out and replaced by a new system, SAM. The datasets, programmes and associated documentation for TB Maps and Stats are now held in the National Archives. ${ }^{140}$

MAFF's regional veterinary experts had adopted and adapted new computing technologies to help align this new data with their existing practices of disease mapping, deeply rooted in the history of epidemiology. Nineteenth-century pioneers of public health had established field practices of 'shoe-leather epidemiology', ${ }^{141}$ in which investigators would travel to an area experiencing a disease outbreak to learn about local communities and the physical environment from 'physicians, chemists, veterinarians, farmers, politicians, and business owners'. ${ }^{142}$ They would then map this information to help establish spatial relationships between disease victims and potential sources of infection, as in the famous case of John Snow and the Broad Street pump. ${ }^{143}$ This spatial way of understanding and controlling the spread of infectious disease pointed the way towards establishing links between disease and contaminated milk-a key issue for controlling bTB. ${ }^{144}$ Field knowledge and mapping were central to establishing the veterinary case for connections between cattle, badgers and 
M. bovis. This is particularly apparent in Roger Muirhead's early case reports (Fig. 2.1), but similar techniques featured in the Cornwall investigation of 1972, and most of MAFF progress reporting on badger/ bTB. ${ }^{145}$ What geographers usefully describe as 'the spatiality of disease' 146 was not just important for epidemiological research: it also guided the underlying logic of implementing 'stamping out' across animal health policy.

In 1985 MAFF put into place the final recommendation of Zuckerman's report: that another expert review be conducted a few years later. Perhaps to avoid risking a repetition of Zuckerman's autocratic approach, MAFF invited a small committee to conduct the review. The new chair, Prof. George Dunnet, was an ecologist specialising in fisheries, well versed in MAFF and the complexities of science policy. He worked with David Jones, head veterinarian at the Zoological Society of London, and, signalling a key shift, an agricultural economist, Prof. John McInerney of the University of Exeter. This reflected the increasing importance of economics to MAFF, as it underwent further rounds of funding cuts through the 1980s. Over this decade, MAFF also instituted another round of restructuring and now privatisation, furthering government agendas of reducing the role of the state. The advisory role of ADAS was reduced and in 1987 it began charging for agricultural 'extension' advice services to farmers and industry. By the early 1990s MAFF's agricultural research and veterinary services were transformed into 'executive agencies', making it possible to sell their services to public and private users: ADAS, the Veterinary Medicines Directorate, the Central Veterinary Laboratories and the Central Science Laboratory. The Animal Health policy group was brought back together with the remaining parts of the SVS under the management of the CVO, to form a single Animal Health and Veterinary Group, which was promptly demerged once again in 1994, due to 'a lack of transparency in relations between its constituent parts and confused accountability in decision making. ${ }^{147}$

It was in this context of renewed change within MAFF that the Dunnet review was published in the spring of 1986. While the report continued to support culling, it was with considerably less enthusiasm, and the Dunnet group instead challenged the existing scientific, veterinary and policy consensus within MAFF on several fronts. Core veterinary research on the pathology and immunology of the disease in badgers and cattle was accepted: that badgers caught bTB and were likely to act as a significant 'reservoir' for the disease in cattle, while other wildlife was not 
significantly involved. However, Dunnet et al. highlighted significant knowledge gaps in the distribution and broader epidemiology of the disease across the two species. Without 'extensive, long-term field studies, involving the killing of large numbers of badgers and cattle over an extensive area' (a prospect which they considered impractical), they argued it would be impossible to prove that the disease passed from badgers to cattle. ${ }^{148}$ Furthermore, without an accurate diagnostic test for badgers, it was impossible to develop a better understanding of the incidence of bTB in their populations. Given these uncertainties, the Dunnet group argued that MAFF's 'clean-ring' strategy (based on the assumption that localised 'pockets' of infection in badgers could be cleared out) was not viable. ${ }^{149}$ They also conducted their own analyses of MAFF's policy regime-first a time-series analysis of bTB incidence, which concluded that badger culling was not working well enough, and second an economic evaluation, which estimated that the costs of the culling policy outweighed the benefits to the tune of $£ 7$ million. ${ }^{150}$ According to their analyses, badger culling would never be able to pay its own way. ${ }^{151}$

The report made recommendations based upon an assumption that a new, more suitable diagnostic test for bTB in badgers would be 'achievable' in three to five years. ${ }^{152}$ Following their early immunological findings and the collaborative work on typing $M$. bovis strains, CVL researchers were exploring alternative tests which could detect antibodies to the bacterium. ${ }^{153}$ Wider successes in the development of antibody-based diagnostic tests (known as ELISA) for a range of other animal infections may have contributed to this optimistic stance. ${ }^{154}$ The Dunnet group recommended that an 'interim strategy' be implemented in the intervening period. Rather than the 'unattainable' goal of complete and permanent disease eradication in both species, they instead argued that policy should aim 'to limit the transmission of disease from badgers to cattle by dealing with identifiable and avoidable risks, quickly and effectively at a reasonable cost'. ${ }^{155}$ The 'clean ring' strategy, based upon the long-standing MAFF tradition of stamping out, should be abandoned, and badgers should only be culled immediately on and around farms suffering a bTB outbreak where no other source of infection could be found. Finally, the Dunnett group recommended an expansion of research into the problem-while the most urgent priority was developing a diagnostic test for badgers, work on the population biology and epidemiology of the disease was also important. ${ }^{156}$ 
While MAFF accepted the Dunnett recommendations and the Minister immediate pledged to implement them, his statement downplayed the critical nature of the report. ${ }^{157}$ Over the following years, culling was gradually scaled back, while research continued, with a marked increase in the number and range of collaborations with external partners and academic scientists. ${ }^{158}$ However, this optimism was short-lived. While a functioning ELISA test was developed, its sensitivity was heavily affected by the progression of the disease. In other words, it worked best for older badgers with active symptoms of disease (e.g. tuberculous lesions), when what was really needed for policy was the opposite. ${ }^{159}$ While the ELISA test was useful for research, it turned out not to be robust enough to change the policy assessments made by Dunnet et al. Therefore the 'interim strategy' remained in place, not for the envisaged five years, but instead for over ten. Meanwhile, a newly unfolding animal health crisis was occupying most of MAFF's attention. While the first case of Bovine spongiform encephalopathy (BSE) was identified in 1986, MAFF announced the existence of this entirely new disease in 1987 , confirming that 132 new cases had already been found. ${ }^{160}$ BSE was declared a notifiable disease in 1988 and a pandemic in 1989: given the completely unknown nature of the problem, the major part of MAFF veterinary research, investigation and surveillance teams were devoted to understanding and controlling this catastrophic new animal health problem. When BSE was found to be transmissible to humans, the public and political pressure on MAFF reached even greater heights, especially given their disastrous strategy of reassuring the public that British beef was 'safe'. ${ }^{161}$ In the heat and light of an expanding and increasingly political animal health crisis, the chronic yet still unresolved problem of bTB faded into obscurity, where it was to stay for many years.

\subsection{Managing M. bovis Through Animal Health CARE}

In this chapter, we have investigated how MAFF's veterinary scientists, field officers and policymakers got to grips with researching and acting upon the newly identified problem of bTB in badgers. Veterinarians have had a formal role as expert advisers within the British Government for over a century, making them central and long-standing members of the animal health epistemic community. As such, understanding how their working practices created reliable knowledge for policy_and were mutually shaped 
by caring practices - is critical to understanding their approach to badger/ bTB. While animal health 'cultures of care' originated in partnerships between farmers, veterinarians and policymakers, 'stamping out' practices of disease control are still traumatic for farmers facing the loss of their animals. These tensions are caused by conflicts between practices of caring for specific farms and herds, and those needed for caring for entire populations and the wider economic interests of the country.

Having explored how care and caring practices operate in the epistemic community around animal health in Britain, we can see how they have guided processes of policymaking and veterinary research as MAFF struggled with the unexpectedly sticky problem of badger/bTB. The spatial logic of 'stamping out'-long established for managing infectious diseases including $\mathrm{bTB}$ - was applied to the new problem of tuberculous badgers. Research practices in the SVS were guided by an implicit multidisciplinarity, in which specialists in multiple fields-particularly laboratory and field investigators-worked in partnership on shared problems, while preserving disciplinary boundaries. The 'shoe-leather epidemiology' of regional veterinary officer Roger Muirhead was supplemented with further expertise from pathology and microbiological testing. ${ }^{162}$ Once MAFF recognised the scale of the problem, this developed into a full-scale scale research programme, employing the above approaches, plus increasingly sophisticated work in fields such as immunology and epidemiology. As the programme moved into the 1980s, MAFF increasingly collected data on bTB and other infectious diseases, adopting new computing technologies to create centralised resources to collate the information. The lab-field loop was reinforced once more when regional veterinary investigators found ways of adapting PCs to converge this data with older field epidemiology practices of mapping, making it much more useful for day-to-day working practice.

We can also see how changes in government administrations-and their attendant political ideologies — have shaped changes in badger/bTB policy. Under the Conservative Heath government, MAFF took a laissezfaire, hands-off advisory approach to badger culling, which was rapidly brought under state control (and implementation) when Labour took power again in 1974. Despite its radical, modernising agenda, the inception of the Thatcher government did not bring change but an attempt to bolster support for existing MAFF policy, albeit in the guise of an expert review. It was scientific research, and the unexpected resistance of badgers to cyanide gassing, which forced policy change in 1982, and 
agendas such as privatisation affected MAFF more towards the end of the decade. The Zuckerman review had inadvertently started a cycle of broken expectations between science, policy and wider society which was to continue through the history of badger/bTB to the present day.

\section{Notes}

1. See Sect. 1.2; also e.g. Haas, 'Introduction'; Meyer and MolyneuxHodgson, 'Introduction: The Dynamics of Epistemic Communities'; Dunlop, 'Epistemic Communities'.

2. Grant, 'Intractable Policy Failure: The Case of Bovine TB and Badgers', 561.

3. Davies et al., 'Science, Culture, and Care in Laboratory Animal Research'.

4. E.g. Mol, Moser and Pols, Care in Practice.

5. Mol, The Logic of Care.

6. See Sect. 1.2, also Davies et al., 'Science, Culture, and Care in Laboratory Animal Research'.

7. Worboys, 'Germ Theories of Disease and British Veterinary Medicine, 1860-1890'; Keir Waddington, 'To Stamp out "so Terrible a Malady": Bovine Tuberculosis and Tuberculin Testing in Britain, 1890-1939', Medical History 48(1) (January 2004): 29-48; Woods, A Manufactured Plague; Abigail Woods, 'Patterns of Animal Disease', in Routledge History of Disease, ed. Mark Jackson (New York: Routledge, 2016), 147-64; Paul Brassley, 'Murrains to Mad Cows: A Very Short History of Governments, People and Animal Diseases', in Contested Countryside: Rural Politics and Land Controversy in Modern Britain, ed. Jeremy Burchardt and Philip Conford (London: I.B.Tauris, 2008), 145-67.

8. J. Law, 'Care and Killing: Tensions in Veterinary Practice', in Care in Practice: On Tinkering in Clinics, Homes and Farms, ed. A. Mol, I. Moser and J. Pols (Bielefeld: Transcript, 2010), 57-69; Abigail Woods, 'From Cruelty to Welfare: The Emergence of Farm Animal Welfare in Britain, 1964-1971', Endeavour 36(1) (2012): 14-22; Henry Buller and Emma Roe, Food and Animal Welfare (London: Bloomsbury, 2016); Kerstin Weich and Herwig Grimm, 'Editorial', Food Ethics 1(3) (1 March 2018): 205-8.

9. Vanessa Ashall, Kate M. Millar and Pru Hobson-West, 'Informed Consent in Veterinary Medicine: Ethical Implications for the Profession and the Animal "Patient", Food Ethics 1(3) (1 March 2018): 247-58.

10. Patricia Morris, 'Introduction: Euthanasia in Veterinary Medicine', in Blue Juice: Euthanasia in Veterinary Medicine (Philadelphia: Temple University Press, 2012), 1-18; Nora Schuurman, 'Performing Good 
Death at the Veterinary Clinic: Experiences of Pet Euthanasia in Finland', Area 49(2) (2016): 208-14; Law, 'Care and Killing'.

11. Lindsay Hamilton, 'Bridging the Divide between Theory and Practice: Taking a Co-Productive Approach to Vet-Farmer Relationships', Food Ethics 1(3) (1 March 2018): 221-33.

12. Cassidy et al., 'Animal Roles and Traces in the History of Medicine, c.1880-1980'; Woods et al., Animals and the Shaping of Modern Medicine.

13. Andrew Gardiner, 'The Animal as Surgical Patient: A Historical Perspective in the 20th Century', History and Philosophy of the Life Sciences 31(3-4) (2009): 355-76.

14. Michael Bresalier, Angela Cassidy and Abigail Woods, 'One Health in History', in One Health: The Theory and Practice of Integrated Health Approaches, ed. Jakob Zinsstag et al. (Wallingford, Oxfordshire: CABI, 2015), 1-15.

15. Abigail Woods and Stephen Matthews, "Little, If at All, Removed from the Illiterate Farrier or Cow-Leech": The English Veterinary Surgeon, c.1860-1885, and the Campaign for Veterinary Reform', Medical History 54(1) (January 2010): 29-54.

16. Brassley, 'Murrains to Mad Cows'; Paul Brassley, 'Wartime Productivity and Innovation, 1939-1945', in The Front Line of Freedom: British Farming in the Second World War (Exeter: British Agricultural History Society, 2006); Woods, 'A Historical Synopsis of Farm Animal Disease and Public Policy in Twentieth Century Britain'.

17. Anne Hardy, 'Professional Advantage and Public Health: British Veterinarians and State Veterinary Services, 1865-1939', 20 Century British History 14(1) (January 2003): 1-23; Anne Hardy, 'John Bull's Beef: Meat Hygiene and Veterinary Public Health in England in the Twentieth Century', Review of Agricultural and Environmental StudiesRevue d'Etudes en Agriculture et Environnement 91(4) (2010): 369-92; Woods and Matthews, 'Little, If at All, Removed from the Illiterate Farrier or Cow-Leech'.

18. James Wilsdon, 'The Past, Present and Future of the Chief Scientific Advisor', European Journal of Risk Regulation 5(03) (September 2014): 293-99.

19. Abigail Woods, 'From Practical Men to Scientific Experts: British Veterinary Surgeons and the Development of Government Scientific Expertise, c. 1878-1919', History of Science (2013), 457-80.

20. While CVL was run by MAFF, Pirbright was run by the Agricultural Research Council (now BBSRC), in line with the wider organisation of agricultural research institutes during the twentieth century-see Colin Thirtle, Paolo Palladino and Jenifer Piesse, 'On the Organisation of Agricultural Research in the United Kingdom, 1945-1994: A Quantitative 
Description and Appraisal of Recent Reforms', Research Policy 26(4-5) (December 1997): 557-76; Parker, Miles. 'The Rothschild Report (1971) and the Purpose of Government-Funded R\&D-a Personal Account'. Palgrave Communications 2 (2 August 2016): 16053. https:// doi.org/10.1057/palcomms.2016.53.

21. Woods, 'A Historical Synopsis of Farm Animal Disease and Public Policy in Twentieth Century Britain'; Woods, 'From Practical Men to Scientific Experts'.

22. Christoph Gradmann, 'Robert Koch and the Invention of the Carrier State: Tropical Medicine, Veterinary Infections and Epidemiology around 1900', Studies in History and Philosophy of Biological and Biomedical Sciences 41(3) (September 2010): 232-40.

23. Woods, A Manufactured Plague, 95.

24. Convery, Ian, Maggie Mort, Cathy Bailey, and Josephine Baxter, 'The Health and Social Consequences of the 2001 Foot \& Mouth Disease Epidemic in North Cumbria', Animal Disease and Human Trauma (Palgrave Macmillan, 2008), 1-153; Woods, A Manufactured Plague, 131-51; Martin Döring and Brigitte Nerlich, The Social and Cultural Impact of Foot and Mouth Disease in the UK in 2001: Experiences and Analyses (Manchester: Manchester University Press, 2009); we will return to the 2001 FMD outbreak in Chap. 6.

25. William A. Maloney, Grant Jordan and Andrew M. McLaughlin, 'Interest Groups and Public Policy: The Insider/Outsider Model Revisited', Journal of Public Policy 14(1) (1994): 17-38.

26. Naylor et al., 'The "Good Farmer"'; Wilkie, Livestock/Deadstock.

27. Law and Mol, 'The Actor Enacted'; Lewis Holloway and Christopher Bear, 'Bovine and Human Becomings in Histories of Dairy Technologies: Robotic Milking Systems and Remaking Animal and Human Subjectivity', BJHS Themes 2 (January 2017): 215-34; Rees, 'Animal Agents?'

28. Colter Ellis, 'The Symbiotic Ideology: Stewardship, Husbandry, and Dominion in Beef Production', Rural Sociology 78(4) (1 December 2013): 429-49; Naylor et al., 'The "Good Farmer"'; Claudia Baldwin, Tanzi Smith and Chris Jacobson, 'Love of the Land: Social-Ecological Connectivity of Rural Landholders', Journal of Rural Studies 51 (2017): 37-52; Sarah L. Crowley, Steve Hinchliffe and Robbie A. McDonald, 'Killing Squirrels: Exploring Motivations and Practices of Lethal Wildlife Management', Environment and Planning E: Nature and Space 1(1-2) (2018): 120-43.

29. Wilkie, Livestock/Deadstock; Colter Ellis, 'Boundary Labor and the Production of Emotionless Commodities: The Case of Beef Production', Sociological Quarterly 55(1) (January 2014): 92-118.

30. Law, 'Care and Killing'; J. Law and I. Moser, 'Contexts and Culling', Science, Technology \& Human Values 37(4) (December 2011): 332-54; 
Qurat UlAin et al., 'Is a "Good Death" at the Time of Animal Slaughter an Essentially Contested Concept?' Animals 7(12) (14 December 2017): 99.

31. Steve Pile, “'A Load of Bloody Idiots": Somerset Dairy Farmers' View of Their Political World', Political Geography Quarterly 10(4) (October 1991): 405-21; Shortall et al., 'True Cowmen and Commercial Farmers'.

32. Frank Butcher, 'TB time-bomb under a county's dairy farmers: 'It happened to me and it could happen again". Farmer's Weekly, 22 June 1971, 51. In NA MAF 109/294, item 9.

33. Mort et al., 'The Health and Social Consequences of the 2001 Foot \& Mouth Disease Epidemic in North Cumbria'; Convery et al., 'Death in the Wrong Place?'; Döring and Nerlich, The Social and Cultural Impact of Foot and Mouth Disease in the UK in 2001.

34. G. Enticott and F. Vanclay, 'Scripts, Animal Health and Biosecurity: The Moral Accountability of Farmers' Talk about Animal Health Risks', Health, Risk \& Society 13(4) (June 2011): 293-309; G. Enticott, 'Techniques of Neutralising Wildlife Crime in Rural England and Wales', Journal of Rural Studies 27(2) (April 2011): 200-8.

35. Woods, 'Patterns of Animal Disease'.

36. William Beinart and Karen Brown, African Local Knowledge of Livestock Health: Diseases \& Treatments in South Africa (Woodbridge: Boydell \& Brewer Ltd., 2013); Alex M. Nading, 'Humans, Animals, and Health: From Ecology to Entanglement', Environment and Society: Advances in Research 4(1) (December 2013): 60-78; Karen Brown, 'Environmental and Veterinary History-Some Themes and Suggested Ways Forward', Environment and History 20(4) (November 2014): 547-59; Delia Grace, 'Zoonoses of Poverty: Measuring and Managing the Multiple Burdens of Zoonoses and Poverty', in Zoonoses-Infections Affecting Humans and Animals: Focus on Public Health Aspects (Dordrecht: Springer Netherlands, 2015), 1127-37.

37. Woods, 'A Historical Synopsis of Farm Animal Disease and Public Policy in Twentieth Century Britain'.

38. G. Enticott, 'Relational Distance, Neoliberalism and the Regulation of Animal Health', Geoforum 52 (March 2014): 42-50; Maye et al., 'Animal Disease and Narratives of Nature'.

39. Michael P. Duffy, 'The Rothschild Experience: Health Science Policy and Society in Britain', Science, Technology \& Human Values 11(1) (1986): 68-78; Parker, 'The Rothschild Report (1971) and the Purpose of Government-Funded R\&D'.

40. N. A. Phillips, J. Bridgeman and M. Ferguson-Smith, 'The Inquiry into BSE and Variant CJD in the United Kingdom' (London: HMSO, 2000), sec. annex 1; G. Enticott et al., 'The Changing Role of Veterinary Expertise in the Food Chain', Philosophical Transactions of the Royal Society of London. Series B, Biological Sciences 366(1573) (July 2011): 
1955-65; Woods, 'A Historical Synopsis of Farm Animal Disease and Public Policy in Twentieth Century Britain.'

41. Pearce, Pugh and Ritchie, Animal Health, 342.

42. Muirhead, 'Bovine Tuberculosis in Wild Badgers in South Gloucestershire'; Muirhead, Gallagher and Burn, 'Tuberculosis in Wild Badgers in Gloucestershire: Epidemiology'; Gallagher, Muirhead and Burn, 'Tuberculosis in Wild Badger (Meles Meles) in Gloucestershire-Pathology'.

43. MAFF, 'Bovine Tuberculosis in Badgers. Report by the Ministry of Agriculture, Fisheries and Food', sec. app. 6; MAFF, 'Bovine Tuberculosis in Badgers. Second Report by the Ministry of Agriculture, Fisheries and Food' (London: Ministry of Agriculture, Fisheries \& Food: HMSO, December 1977), sec. app. 5.

44. MAFF, 'Bovine Tuberculosis in Badgers. Third Report by the Ministry of Agriculture, Fisheries and Food' (London: Ministry of Agriculture, Fisheries \& Food: HMSO, July 1979), 17.

45. Gallagher and Nelson, 'Cause of Ill Health and Natural Death in Badgers in Gloucestershire'.

46. Brown, 'Animal Health 1974: Report of the Chief Veterinary Officer', 53; T. W. Little, K. J. Burn and P. Stuart, 'Virulence for Calves of Tubercle Bacilli Isolated from Badgers', Veterinary Record 96(24) (1975): 533; MAFF, 'Bovine Tuberculosis in Badgers. Report by the Ministry of Agriculture, Fisheries and Food'.

47. MAFF, 'Bovine Tuberculosis in Badgers. Third Report by the Ministry of Agriculture, Fisheries and Food', 13; Little, Naylor and Wilesmith, 'Laboratory Study of Mycobacterium Bovis Infection in Badgers and Calves'; Overy and Tansey, A History of Bovine TB c.1965-c. 2000, 14-15.

48. MAFF, 'Bovine Tuberculosis in Badgers. Report by the Ministry of Agriculture, Fisheries and Food', 7.

49. MAFF, 'Bovine Tuberculosis in Badgers. Third Report by the Ministry of Agriculture, Fisheries and Food', 15.

50. MAFF, 'Bovine Tuberculosis in Badgers. Third Report by the Ministry of Agriculture, Fisheries and Food' (London: Ministry of Agriculture, Fisheries \& Food: HMSO, July 1979), 10.

51. MAFF, 'Bovine Tuberculosis in Badgers. Report by the Ministry of Agriculture, Fisheries and Food', 1; Overy and Tansey, A History of Bovine TB c.1965-c. 2000, 36-38, 41-42. For citizen science, see e.g. Rick Bonney et al., 'Next Steps for Citizen Science', Science 343(6178) (2014): 1436-37. For a recent return to the badger survey, see Jessica Phoenix, 'Local Understandings of Bovine Tuberculosis (Working Title)' (PhD, University of Lancaster, in prep.); Elsa Sandoval Barron et al., 'A Study of Tuberculosis in Road Traffic-Killed Badgers on the Edge of the British Bovine TB Epidemic Area', Scientific Reports 8(1) (6 December 2018): 17206. 
52. H. V. Thompson, 'Note LP/N 3868C to Richard Clark, 17 July 1974', NA MAF $109 / 383$, item 154.

53. E. Dennis, 'Memo to I. Prest: Badgers/Bovine TB in Dorset', 24 July 1975, NA FT 41/91; H. V. Thompson, 'Memo to D.W.M. Herbert: Badgers and Tuberculosis in Cattle', 20 January 1975, NA MAF 109/384, item 30.

54. MAFF, 'Bovine Tuberculosis in Badgers. Report by the Ministry of Agriculture, Fisheries and Food', 3.

55. Clifton-Hadley et al., 'The Occurrence of Mycobacterium Bovis Infection in Cattle in and around an Area Subject to Extensive Badger (Meles Meles) Control', 181.

56. MAFF, 'Bovine Tuberculosis in Badgers. Third Report by the Ministry of Agriculture, Fisheries and Food', 4-5.

57. Clifton-Hadley et al., 'The Occurrence of Mycobacterium Bovis Infection in Cattle in and around an Area Subject to Extensive Badger (Meles Meles) Control'.

58. MAFF, Press Release: Consultative Panel on Badgers and Tuberculosis, September 241975 (MAFF: London, 1975).

59. For further details on the development and use of Cymag in mammalian pest control, see Sect. 4.1.

60. MAFF, 'Bovine Tuberculosis in Badgers. Report by the Ministry of Agriculture, Fisheries and Food', 4.

61. MAFF, 'Bovine Tuberculosis in Badgers. Report by the Ministry of Agriculture, Fisheries and Food'; MAFF, 'Bovine Tuberculosis in Badgers. Second Report by the Ministry of Agriculture, Fisheries and Food'; MAFF, 'Bovine Tuberculosis in Badgers. Third Report by the Ministry of Agriculture, Fisheries and Food'.

62. H. W. Rees, 'Animal Health 1980: Report of the Chief Veterinary Officer' (London: Ministry of Agriculture, Fisheries and Food, 1980).

63. MAFF, 'Bovine Tuberculosis in Badgers. Third Report by the Ministry of Agriculture, Fisheries and Food', 3, 12.

64. J. F. D. Frazer, 'In Confidence: Badgers and Bovine TB Investigation', 8 September 1971, NA FT 41/88; I. Presst (Deputy Director), 'Badgers', 6 March 1974, NA FT/41/89.

65. Anon., 'Ministry Slammed Over "Needless” Badger Slaughter', Gloucester Citizen, 29 May 1977, 1; Ian Beales, 'How Much Longer Must this Blitz on Badgers Go On?’ Western Daily Press, 14 Feb. 1979, 1.

66. See Chap. 5, also Thirtle, Palladino and Piesse, 'On the Organisation of Agricultural Research in the United Kingdom, 1945-1994', 565-66; Woods, 'From Cruelty to Welfare'; Sayer, 'Animal Machines'.

67. E. Clarkson, 'Badger gassing: just a job for two men, expendable mercenaries', The Guardian, 5 September 1979, 8; see also Zuckerman, 'Badgers, Cattle and Tuberculosis', 7. 
68. MAFF, Press Release: Badgers and Bovine Tuberculosis, 25 September 1979 (MAFF: London).

69. Ibid.

70. Woods, A Manufactured Plague, 123; Pemberton and Worboys, Mad Dogs and Englishmen, 175-76; John Sheail, "Torrey Canyon": The Political Dimension', Journal of Contemporary History 42(3) (2007): 485-504.

71. P. Mountbatten, 'Letter to Solly Zuckerman', 29 April 1974, ZUEA S2 PUB 425.

72. S. L. Zuckerman, 'Letter to HRH Duke of Edinburgh', 14 May 1974, ZUEA, S2 PUB 425.

73. For an overview of Zuckerman's life and research see P. L. Krohn, 'Solly Zuckerman Baron Zuckerman, of Burnham Thorpe, O.M., K.C.B', Biogr. Mems Fell. R. Soc. 41 (1995): 576-98.

74. Zuckerman, 'Badgers, Cattle and Tuberculosis', 103-7.

75. Zuckerman, 'Badgers, Cattle and Tuberculosis', 47.

76. Rees, 'Animal Health 1980', 1-2.; H. Clayton, 'Killing of tubercular badgers by gas to be resumed', The Times, 31 October 1980, 1.

77. D. Johnson, 'Badger the suspect in cattle epidemic', The Guardian, 27 October 1980.

78. Anon., 'RUN, BADGER, RUN The scientists are after you!' Daily Express, 31 October 1980, 15.

79. W. Newlands, 'Boycott goes to bat for the badger', Daily Mail, 10 December 1980, 38.

80. Stephen Harris, 'Badgers and TB', Nature 288 (11 December 1980): 532.

81. Anon., 'Scientists badger Lord Zuckerman over gassing', New Scientist, 4 December 1960, 619.

82. S. L. Zuckerman, 'OPINION: THE BADGER AND TB CONTROVERSY', Sunday Times, 4 January 1981, 12; Nature and S. L. Zuckerman, 'The Great Badger Debate', Nature 289(5799) (19 February 1981): 628-30.

83. See the letters pages of Nature vol. 289, issues 5794-5800; vol. 292, issue 5819; also M. Kaplan, 'Keep badgering', New Scientist, 10 January 1985.

84. E. Grice and O. Gillie, 'Badgers May Be Innocent, OK?' Sunday Times, 27 December 1980; P. Oldfield, 'Badgered to Death', Guardian, 15 May 1981,15 ; P. Drabble, 'Brock is Innocent, OK? Gassing Badgers is Wrong', Observer Magazine, 27 September 1981, 33-39; A. Waugh, 'When top people are killed', Sunday Telegraph, 22 November 1981. All clippings in ZUEA S2 PUB 425.

85. A. Goodman, 'Letter to Lord Zuckerman', 26 November 1981. ZUA, S2 PUB 425, folder '1980-1985 press cuttings'. 
86. RSPCA Wild Animals Advisory Committee, 'Badgers and Bovine Tuberculosis : The Case for Further Investigation' (Horsham: Royal Society for the Prevention of Cruelty to Animals, 1979), British Library. NA MAF 459/8, items 1-25.

87. J. Edginton and R. Lynch, 'THE TOXICITY OF HYDROGEN CYANIDE BY INHALATION TO FERRETS AND BADGERS' (Salisbury: Chemical Defense Establishment, Porton Down, 1982), in NA MAF 459/8. For ferrets as model organisms, see Michael Bresalier, 'Neutralizing Flu: "Immunological Devices" and the Making of a Virus Disease', in Crafting Immunity: Working Histories of Clinical Immunology, ed. Kenton Kroker, Jennifer Keelan and Pauline Mazumdar (Farnham: Ashgate, 2008), 107-45.

88. Edginton and Lynch, 'THE TOXICITY OF HYDROGEN CYANIDE BY INHALATION TO FERRETS AND BADGERS', 9-10; anon., 'CONFIDENTIAL: BADGERS AND TB-METHODS OF BADGER CONTROL', 2 June 1982, NA MAF 459/8, item 20.

89. Anon., 'NOTE OF A MEETING HELD AT 10.30am ON TUESDAY IST JUNE 1982 TO DISCUSS THE CHEMICALESTABLISHMENT'S REPORT ON EXPERIMENTS INTO THE TOXICITY OF HYDROGEN CYANIDE BY INHALATION TO FERRETS AND BADGERS', I June 1982, NA MAF 459/8, item 17.

90. Anon., 'NOTE OF A MEETING ...', l June 1982, NA MAF 459/8, item 17.

91. Anon., 'CONFIDENTIAL: THE TOXICITY OF HYDROGEN CYANIDE. MINUTES OF A MEETING', 15 June 1982, NA MAF $459 / 10$, item 22.

92. Ibid.

93. J. Hepburn, 'CONFIDENTIAL. BADGERS AND TB-METHODS OF BADGER CONTROL', 23 June 1982, NA MAF 459/10, item 26, 3.

94. P. Walker, 'Letter to Lord Zuckerman: TB in Badgers', ZUEA, S2 PUB 425; MAFF 1 July 1982; PRESS NOTICE, 1 JULY 1982 MINISTER'S STATEMENT (MAFF: London); CONSULTATIVE PANEL ON BADGERS AND TUBERCULOSIS: Minutes of 23rd Meeting of the Panel, 23 July 1982, NA MAF 459/8, item 59.

95. J. Hepburn, 'CONFIDENTIAL. BADGERS AND TB-METHODS OF BADGER CONTROL', 23 June 1982, NA MAF 459/10, item 26, 6.

96. S. Young, 'Badger Poison Gas War Halted', Daily Mirror, 2 July 1982, 9; D. Johnson, 'Cyanide killing of badgers halted', The Guardian, 2 July 1982, 24; C. White, 'Badger gassing halted after "cruelty" warning', Daily Mail, 2 July 1982, 11.

97. Anon., 'SO CRUEL', Daily Mirror, 4 July 1982. In ZUEA Z2 PUB 425, folder '1982-1985, Press cuttings in year order only'.

98. A. Waugh, 'Auberon Waugh's Diary', Private Eye 525, 29 January 1982. 
99. S. L. Zuckerman, 'Letter to Sir Robert Armstrong', 12 January 1981, ZUEA S2 PUB 425.

100. Anonymous letter dated 1 November 1980, ZUEA, S2 PUB 425, see also 'Nut Letters' folder in S2 PUB 425.

101. 'Mrs. Murray' is badger protection activist Ruth Murray, discussed in Chap. 2 and again in Chap. 5.

102. R. Armstrong, 'Note to Solly Zuckerman', 6 January 1981, ZUEA, S2 PUB 425.

103. P. Walker, 'Letter to Lord Zuckerman', 8 January 1981, ZUEA, S2 PUB 425 .

104. S. L. Zuckerman, 'Note to Peter Walker', 19 January 1981, ZUEA, Z2 PUB 425.

105. Krohn, 'Solly Zuckerman Baron Zuckerman, of Burnham Thorpe, O.M., K.C.B', 587-88.

106. S. L. Zuckerman, 'Letter to Peter Walker', 13 February 1981, ZUEA, Z2 PUB 425.

107. P. Walker, 'Letter to Lord Zuckerman', 27 February 1981, ZUEA, Z2 PUB 425.

108. This included Zuckerman's work on various science-policy reviews, the creation of the UK Government's Department of the Environment and the Natural Environment Research Council, early advocacy for concerns about global warming, and the influential School of Environmental Sciences at the University of East Anglia. See Krohn, 'Solly Zuckerman Baron Zuckerman, of Burnham Thorpe, O.M., K.C.B.'; Jon Agar, "“Future Forecast-Changeable and Probably Getting Worse": The UK Government's Early Response to Anthropogenic Climate Change', Twentieth Century British History 26(4) (December 2015): 602-28; Clark, 'Pesticides, Pollution and the UK's Silent Spring, 1963-64'.

109. Krohn, 'Solly Zuckerman Baron Zuckerman, of Burnham Thorpe, O.M., K.C.B.'

110. Krohn, 'Solly Zuckerman Baron Zuckerman, of Burnham Thorpe, O.M., K.C.B.', 587.

111. S. L. Zuckerman, 'Note to Peter Walker', 28 September 1981, ZUEA, Z2 PUB 425, folder '1980-1985 press cuttings'.

112. Zuckerman, 'Badgers, Cattle and Tuberculosis', para. 36.; S. L. Zuckerman, 'Letter to Peter Walker', 28 September 1981, ZUEA S2 PUB 425.

113. Jonathan Burt, 'Solly Zuckerman: The Making of a Primatological Career in Britain, 1925-1945', Studies in History and Philosophy of Biological and Biomedical Sciences 37(2) (June 2006): 295-310; Robert G. W. Kirk, 'Between the Clinic and the Laboratory: Ethology and Pharmacology in the Work of Michael Robin Alexander Chance, c.1946-1964', Medical History 53(4) (October 2009): 513-36. 
114. S. L. Zuckerman, 'Letter to J.R.R. Jeffers, Head of Institute of Terrestrial Ecology', 28 February 1981, ZUEA S2PUB 425.

115. S. L. Zuckerman, 'Letter to Sir Herman Bondi', 27 February 1981, ZUEA S2PUB 425.

116. S. L. Zuckerman, 'Letter to Sir Herman Bondi', 23 March 1981, ZUEA S2PUB 425.

117. S. L. Zuckerman, 'Letter to Sir Herman Bondi', 23 March 1981, ZUEA S2PUB 425.

118. Nature and Zuckerman, 'The Great Badger Debate', 630.

119. Zuckerman, 'Badgers, Cattle and Tuberculosis', 9-10.

120. The gendered dimension of these debates has not escaped me, and will be discussed in Sect. 5.4.

121. Zuckerman, 'Badgers, Cattle and Tuberculosis', 71-78.

122. Agar, 'What Happened in the Sixties?'; Agar, 'Transition: Sea Change in the Long 1960s'.

123. E. N. Wright, 'Confidential: Badger Control Operations-Implications of switching from gassing to trapping', 11 June 1982, NA MAF 459/8, item 27; MAFF, 'Press Notice: Minister's Statement to the Consultative Panel', 1 July 1982, NA MAF 459/8, item 50; MAFF, 'Bovine Tuberculosis in Badgers. Seventh Report by the Ministry of Agriculture, Fisheries and Food' (London: Ministry of Agriculture, Fisheries \& Food: HMSO, August 1983), 2.

124. MAFF, Bovine Tuberculosis in Badgers. Seventh Report, 2-3; MAFF, 'Bovine Tuberculosis in Badgers. Eighth Report by the Ministry of Agriculture, Fisheries and Food' (London: Ministry of Agriculture, Fisheries \& Food: HMSO, August 1984), 2; Dunnet, Jones and McInerney, 'Badgers and Bovine Tuberculosis', 6 .

125. Zuckerman, 'Badgers, Cattle and Tuberculosis', para. 48.

126. MAFF, 'Bovine Tuberculosis in Badgers. Sixth Report by the Ministry of Agriculture, Fisheries and Food' (London: Ministry of Agriculture, Fisheries \& Food: HMSO, August 1982), 22-28; 'MAFF Consultative Panel on Badgers and bTB, minute of meeting', 23 July 1982, NA MAF $459 / 8$, item 59 .

127. Stuart and Wilesmith, 'Tuberculosis in Badgers'; C. L. Cheeseman, J. W. Wilesmith and F. A. Stuart, 'Tuberculosis-The Disease and Its Epidemiology in the Badger, A Review', Epidemiology and Infection 103(1) (August 1989): 113-25; Clifton-Hadley et al., 'The Occurrence of Mycobacterium Bovis Infection in Cattle in and around an Area Subject to Extensive Badger (Meles Meles) Control'.

128. P. A. Barrow, 'Aspects of the Epidemiology of Bovine Tuberculosis in Badgers and Cattle. II. The Development and Use of a Typing System for Mycobacterium Bovis', The Journal of Hygiene 86(3) (1981): 247-57; P. A. Barrow and J. Gallagher, 'Aspects of the Epidemiology of Bovine 
Tuberculosis in Badgers and Cattle. I. The Prevalence of Infection in Two Wild Animal Populations in South-West England', The Journal of Hygiene 86(3) (1981): 237-45.

129. MAFF Wildlife Unit, The Thornbury Study Area: 1989 survey (MAFF: London, private collection); see also Clifton-Hadley et al., 'The Occurrence of Mycobacterium Bovis Infection in Cattle in and around an Area Subject to Extensive Badger (Meles Meles) Control'.

130. See, e.g. MAFF, 'A review of bovine tuberculosis in Great Britain' (MAFF: London, September 1984), in ZUEA, S2PUB 425.

131. A. C. L. Brown, 'Animal Health 1972: Report of the Chief Veterinary Officer' (London: Ministry of Agriculture, Fisheries and Food, 1972), 56-57.

132. A. C. L. Brown, 'Animal Health 1973: Report of the Chief Veterinary Officer' (London: Ministry of Agriculture, Fisheries and Food, 1973), 62-64. For the wider history of computing across Whitehall, see Jon Agar, The Government Machine: A Revolutionary History of the Computer (Cambridge, MA: MIT Press, 2003). For brucellosis, see Karen Sayer, 'Brucellosis in Fact and Fiction: The Story of a Zoonosis', Veterinary History 18 (2016): 165-83.

133. See, e.g. Zuckerman, 'Badgers, Cattle and Tuberculosis', paras 69-75; Barrow, 'Aspects of the Epidemiology of Bovine Tuberculosis in Badgers and Cattle. II. The Development and Use of a Typing System for Mycobacterium Bovis'; Barrow and Gallagher, 'Aspects of the Epidemiology of Bovine Tuberculosis in Badgers and Cattle. I. The Prevalence of Infection in Two Wild Animal Populations in South-West England'.

134. Wilesmith became head of the VLA's epidemiology department in 1986 and subsequently led MAFF's investigations into BSE. Anon., 'Zuckerman Review: Meeting with senior veterinary staff of the Ministry', 24 April 1980, ZUEA S2 PUB 155; J. W. Wilesmith, 'A case-control study of M. bovis in cattle herds in relation to badger sett density', MAFF, 1980, ZUEA S2 PUB 115.

135. MAFF, 'Bovine Tuberculosis in Badgers. Eighth Report by the Ministry of Agriculture, Fisheries and Food', 9; H. W. Rees, 'Animal Health 1984: Report of the Chief Veterinary Officer' (London: Ministry of Agriculture, Fisheries and Food, 1984), 57-58; H. W. Rees, 'Animal Health 1986: Report of the Chief Veterinary Officer' (London: Ministry of Agriculture, Fisheries and Food, 1986), 65-66.

136. H. W. Rees, 'Animal Health 1985: Report of the Chief Veterinary Officer' (London: Ministry of Agriculture, Fisheries and Food, 1985), 57-58. For wider trends across UK government, see Agar, The Government Machine, 367-89. 
137. For the culture and media of computing enthusiasts during the 1980s, see Tom Lean, Electronic Dreams: How 1980s Britain Learned to Love the Computer (London: Bloomsbury Academic, 2016).

138. Interview with Roger Sainsbury, 21/05/2015.

139. Interview with Roger Sainsbury, 21/05/2015.

140. NA MAF 430 series; for further information see http://discovery.nationalarchives.gov.uk/details/r/Cl6050.

141. Steere-Williams, 'Performing State Medicine during Its "Frustrating" Years', 98.

142. Jacob Steere-Williams, 'The Perfect Food and the Filth Disease: MilkBorne Typhoid and Epidemiological Practice in Late Victorian Britain', Journal of the History of Medicine and Allied Sciences 65(4) (October 2014): 519.

143. Kari S. McLeod, 'Our Sense of Snow: The Myth of John Snow in Medical Geography', Social Science of Medicine 50(7-8) (April 2000): 923-35; Tom Koch, Disease Maps: Epidemics on the Ground (Chicago: University of Chicago Press, 2011).

144. Waddington, The Bovine Scourge; Peter J. Atkins, Liquid Materialities: A History of Milk, Science and the Law (Farnham: Ashgate, 2010); Olmstead and Rhodes, Arresting Contagion; Atkins, A History of Uncertainty.

145. Muirhead, 'Bovine Tuberculosis in Wild Badgers in South Gloucestershire'; Richards et al., 'Inquiry into Bovine TB in West Cornwall'; Muirhead, Gallagher and Burn, 'Tuberculosis in Wild Badgers in Gloucestershire: Epidemiology'.

146. Tom Koch and Kenneth Denike, 'Certainty, Uncertainty, and the Spatiality of Disease: A West Nile Virus Example', Stochastic Environmental Research and Risk Assessment 21(5) (August 2007): 523-31; Koch, Disease Maps.

147. A. Lebrecht, 'Stage 2 report: proposals for changes in functions of the Animal Health and Veterinary Group of MAFF', unpublished document, presented as evidence to Phillips, Bridgeman and Ferguson-Smith, 'The Inquiry into BSE and Variant CJD in the United Kingdom', 108. For MAFF's reorganisations during the 1980s and 1990s, see Paul Ingram, 'THE UNITED KINGDOMEXPERIENCE INTHE PRIVATIZATION OF EXTENSION', in Public and Private Roles in Agricultural Development: Proceedings of the Twelfth Agricultural Sector Symposium, ed. J. R. Anderson and C. de Haan (Washington, DC: World Bank Publications, 1988); Thirtle, Palladino and Piesse, 'On the Organisation of Agricultural Research in the United Kingdom, 1945-1994', 566-67; Phillips, Bridgeman and Ferguson-Smith, 'The Inquiry into BSE and Variant CJD in the United Kingdom', 85-112.

148. Dunnet, Jones and McInerney, 'Badgers and Bovine Tuberculosis', 17. 
149. Dunnet, Jones and McInerney, 'Badgers and Bovine Tuberculosis', $12-13,18$.

150. Dunnet, Jones and McInerney, 'Badgers and Bovine Tuberculosis', $22-25$.

151. A. P. Power, B. G. A. Watts and Fisheries and Food, Great Britain, Ministry of Agriculture, The Badger Control Policy: An Economic Assessment (London: Ministry of Agriculture, Fisheries \& Food: HMSO, 1987).

152. Dunnet, Jones and McInerney, 'Badgers and Bovine Tuberculosis', 33.

153. A. C. L. Brown, 'Animal Health 1977: Report of the Chief Veterinary Officer' (London: Ministry of Agriculture, Fisheries and Food, 1977), $59-60$.

154. Rees, 'Animal Health 1984: Report of the Chief Veterinary Officer', 49-50; Rees, 'Animal Health 1985: Report of the Chief Veterinary Officer', 3 .

155. Dunnet, Jones and McInerney, 'Badgers and Bovine Tuberculosis', 28, 38.

156. Dunnet, Jones and McInerney, 'Badgers and Bovine Tuberculosis', 38-39.

157. MAFF, Press Notice, April 7, 1986 Government Will Act Immediately on the Dunnet Report's Main Findings on Badger Control (MAFF: London, 1986).

158. MAFF, 'Bovine Tuberculosis in Badgers. Eleventh Report by the Ministry of Agriculture, Fisheries and Food' (London: Ministry of Agriculture, Fisheries \& Food: HMSO, August 1987), 5-13.

159. MAFF, 'Bovine Tuberculosis in Badgers. Fourteenth Report by the Ministry of Agriculture, Fisheries and Food' (London: Ministry of Agriculture, Fisheries \& Food: HMSO, July 1990), 4-5.

160. H. W. Rees, 'Animal Health 1987: Report of the Chief Veterinary Officer' (London: Ministry of Agriculture, Fisheries and Food, 1987), 13; J. W. Wilesmith et al., 'Bovine Spongiform Encephalopathy: Epidemiological Studies', The Veterinary Record 123(25) (December 1988): 638-44.

161. Miller, 'Risk, Science and Policy'; Phillips, Bridgeman and FergusonSmith, 'The Inquiry into BSE and Variant CJD in the United Kingdom'; Kiheung Kim, The Social Construction of Disease: From Scrapie to Prion (New York: Routledge, 2006).

162. Steere-Williams, 'Performing State Medicine during Its "Frustrating" Years'. 
Open Access This chapter is licensed under the terms of the Creative Commons Attribution 4.0 International License (http://creativecommons.org/licenses/ by $/ 4.0 /$ ), which permits use, sharing, adaptation, distribution and reproduction in any medium or format, as long as you give appropriate credit to the original author(s) and the source, provide a link to the Creative Commons licence and indicate if changes were made.

The images or other third party material in this chapter are included in the chapter's Creative Commons licence, unless indicated otherwise in a credit line to the material. If material is not included in the chapter's Creative Commons licence and your intended use is not permitted by statutory regulation or exceeds the permitted use, you will need to obtain permission directly from the copyright holder.

() (1) 